\title{
Pure Theory of the Federal Funds Rate
}

\author{
Stefan Homburg \\ Hannover Economic Papers (HEP) No. 578 \\ ISSN 0949-9962 \\ 11 August 2016 \\ Revised: 7 February 2017
}

School of Economics and Management, Leibniz University Hannover, Germany. Phone: +49 511 762-5633. Email: homburg@fiwi.uni-hannover.de.

Abstract: The effective federal funds rate is determined in a competitive interbank market, while the target federal funds rate represents a policy variable. This paper proposes a theory of the determination of the effective funds rate. According to the main result, the latter is a Lagrange multiplier that vanishes if excess reserves emerge. This is exactly what happened in the United States in September 2008. A final section considers interest on reserves.

I thank participants of the $11^{\text {th }}$ ifo Dresden Workshop on macroeconomics, particularly Tobias Kranz, for helpful comments. Thanks are also due to Stephan Kohns and Felix Geiger, Deutsche Bundesbank, who commented on an earlier draft.

Keywords: Federal funds rate; excess reserves; money multiplier; zero lower bound.

JEL-Classification: E43, E51, E58, G01 


\section{Introduction}

The effective federal funds rate is an interest rate paid on overnight interbank loans. Banks demand such loans if they wish to increase their reserve balances, and supply them in the opposite case. Thus, the effective funds rate is determined in a competitive market. Quite often, this rate is close to the target federal funds rate, a policy variable that is set by the Federal Open Market Committee (FOMC). In the fall of 2008, however, the two rates began to differ markedly, as will be documented below.

Moreover, the effective funds rate showed large deviations from the market interest rate on long-term government bonds during the last decade. Figure 1 illustrates that during 2004-2007, the effective funds rate climbed steadily from 1 to 5.3 percent, while the yield of 10-years government bonds did not change much, a situation referred to as the US bond yield conundrum. In 2008, however, the effective funds rate plunged to almost zero, where it has remained ever since, whereas the bond rate recovered in 2009.

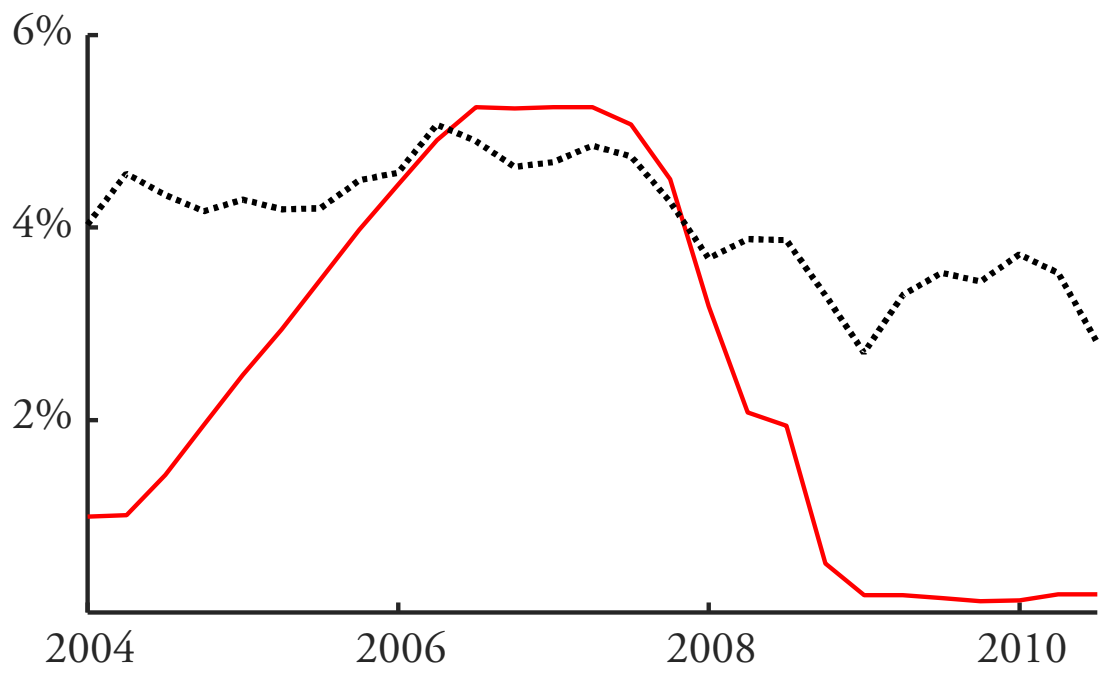

Figure 1: Effective federal funds rate (solid line) versus bond rate (dotted line). Notes: Monthly data, retrieved July 2016 from research.stlouisfed.org/fred2, series DFF and WGS10YR.

Monetary theory focuses on the target funds rate that is determined by decisions of policy makers. However, the Fed does not fix the target funds rate outright but uses open market operations to keep the effective funds rate close to the target. It is not entirely clear (see Fama 2013: 181) whether the FOMC sets the target autonomously or in accordance with the effective funds rate, a practice sometimes referred to as "dirty targeting". Since the effective funds rate is determined by supply and demand in the interbank market and does not always coincide with the target funds rate, one needs a theory that explains its determination.

This paper proposes such a theory. In doing so, it breaks new ground and complements the relevant empirical literature, e.g. Goda (2013), Hamilton (1996), and Rudebusch (1995). Methodically, the present approach follows the accustomed theories of the banking firm. It is also related to Poole's (1968) classical treatment of bank reserve management. None of these contributions, however, endeavored to determine 
the effective funds rate as an equilibrium market rate. The proposed theory is "pure" in the following sense: It abstracts from institutional details such as banks' intraday decision-making over stochastic cash flows, bank heterogeneity, and lagged reserve requirements.

Because central bank policies are quite similar internationally, the results do not pertain exclusively to the Fed and the United States but should be of general interest. Among the main findings are an explanation of why the 'multiplier' approach failed in the aftermath of the financial crisis, and a brief analysis of interest on reserves.

Section 2 reviews the traditional approach. Section 3 augments this model with a market for federal funds that determines the effective funds rate in market equilibrium. Section 4 considers interest management policies. Section 5 analyzes situations where banks keep excess reserves and shows that this drives the effective funds rate toward the zero lower bound, or ZLB. Section 6 considers interest on reserves, and section 7 concludes.

\section{Traditional Model}

The traditional model, which can be traced back to Phillips (1920), includes a central bank and a unit continuum of identical commercial banks. It disregards currency for simplicity. In period $t$, the central bank buys long-term bonds, $B_{t}^{c b} \geq 0$, and creates a corresponding amount of reserves, $R_{t}$. Its balance sheet reads

$$
B_{t}^{c b}=R_{t} .
$$

Commercial banks keep reserves, $R_{t}$, and buy bonds (or make loans) of the amount $B_{t}^{b}$. These two assets correspond to deposit money, $D_{t} \geq 0$, as the sole liability. Thus, a bank's balance sheet reads

$$
R_{t}+B_{t}^{b}=D_{t} .
$$

The bond interest rate, $i_{t}$, is given and no interest is paid on deposits. Deposits induce costs described by a short-run cost function, $J\left(D_{t}\right)$, that satisfies the usual monotonicity and convexity properties, $J^{\prime}, J^{\prime \prime}>0$. Subject to a required reserve ratio $r r \in(0 ; 1)$, which obliges banks to hold reserves of at least $r r \times D_{t}$, each bank solves:

$$
\begin{aligned}
& \max _{B_{t}^{b}} ! \quad i_{t} B_{t}^{b}-J\left(D_{t}\right) \\
& \text { s.t. } \quad r r \times D_{t} \leq R_{t} .
\end{aligned}
$$

Substituting deposits from (2) gives the Lagrange function

$$
\mathcal{L}=i_{t} B_{t}^{b}-J\left(R_{t}+B_{t}^{b}\right)-\xi_{t}^{R}\left(\operatorname{rr}\left(R_{t}+B_{t}^{b}\right)-R_{t}\right) .
$$

Differentiating with respect to the bonds as the only control variable yields

$$
\xi_{t}^{R}=\frac{i_{t}-J^{\prime}\left(D_{t}\right)}{r r} .
$$

The traditional approach assumes $i_{t}-J^{\prime}\left(D_{t}\right)>0$. Retaining this premise, the Lagrange multiplier is strictly positive, and Kuhn-Tucker's complementary slackness 
condition implies that the constraint binds at the optimum; in a deterministic setting, banks hold only required reserves but no excess reserves. The corresponding solutions for bonds and deposits read $B_{t}^{b}=[(1-r r) / r r] R_{t}$ and $D_{t}=R_{t} / r r$, the last being the familiar 'money multiplier' in models without currency.

The positive shadow price $\xi_{t}^{R}$ sustains Gurley and Shaw's (1960: 271) view that reserve requirements make "commercial banks a disequilibrium sector set apart from other sectors of the economy that are guided by the pricing mechanism rather than by direct controls". The shadow price represents the amount of money banks would like to pay for additional reserves. With individual reserves assumed exogenous, however, it is impossible for a single bank to increase its reserves. This gives rise to a disequilibrium situation.

\section{The Market for Federal Funds}

A market for reserves is now introduced. At the going effective funds rate, $i_{t}^{F} \geq 0$, each bank can borrow an amount of $F_{t}^{d}>0$ in the interbank market to increase its reserves to $R_{t}+F_{t}^{d}$. Alternatively, it can lend an amount of $F_{t}^{d}<0$, thus reducing its reserves. With this extension, $R_{t}$ represents the initial amount of reserves created by the central bank, while $R_{t}+F_{t}^{d}$ represents the amount of reserves banks plan to have after borrowing or lending the interbank market. Now, each bank has two choice variables and solves

$$
\begin{array}{cl}
\max _{B_{t}^{b}, F_{t}^{d}} & i_{t} B_{t}^{b}-i_{t}^{F} F_{t}^{d}-J\left(D_{t}\right) \\
\text { s.t. } & \quad r r \times D_{t} \leq R_{t}+F_{t}^{d} .
\end{array}
$$

Borrowing funds extends a bank's balance sheet to $\left(R_{t}+F_{t}^{d}\right)+B_{t}^{b}=D_{t}+F_{t}^{d}$. Lending, by contrast, constitutes an asset swap, an exchange of reserves for claims against fellow banks. Since neither of the two actions affects the identity $R_{t}+B_{t}^{b}=D_{t}$, the latter is still used in forming the Lagrange function

$$
\mathcal{L}=i_{t} B_{t}^{b}-i_{t}^{F} F_{t}^{d}-J\left(R_{t}+B_{t}^{b}\right)-\xi_{t}^{R}\left(\operatorname{rr}\left(R_{t}+B_{t}^{b}\right)-R_{t}-F_{t}^{d}\right) .
$$

Differentiating with respect to the bonds recovers equation (5). Differentiating with respect to the borrowed funds gives the additional optimality condition

$$
i_{t}^{F}=\xi_{t}^{R} \text {. }
$$

This characterizes the effective funds rate as a Lagrange multiplier. In a competitive setting, individual banks take the funds rate, $i_{t}^{F}$, as exogenous and choose bond holdings, interbank borrowing and the implied amount of deposits optimally. The model is now closed by an equilibrium condition for the funds market:

$$
F_{t}^{d}=0 \text {. }
$$

By virtue of this market equilibrium condition, the funds rate becomes endogenous. In equilibrium, all banks refrain from interbank borrowing and lending. Such a symmetric treatment is a special case, of course, and could easily be generalized by admitting bank heterogeneity: With $r_{t}^{j}$ and $f_{t}^{d, j}$ denoting the individual reserves and the 
borrowed funds of bank $j$, respectively, $R_{t}$ and $F_{t}^{d}$ become the corresponding integrals. Then, banks with reserves below the average will borrow in the interbank market, $f_{t}^{d, j}>0$, whereas others will lend, $f_{t}^{d, j}<0$. The ensuing trade volume in the interbank market will generally be positive, whereas it vanishes in the simple case of homogenous banks. However, since bank heterogeneity does in no way affect the model's basic logic, the following analysis returns to the case of homogenous banks.

Figure 2 illustrates the determination of the effective funds rate. In general, all banks wish to borrow, or to lend, at the prevailing funds rate. Competition in the interbank market drives the funds rate to the equilibrium point, shown as a bullet, where the excess demand in the interbank market vanishes.

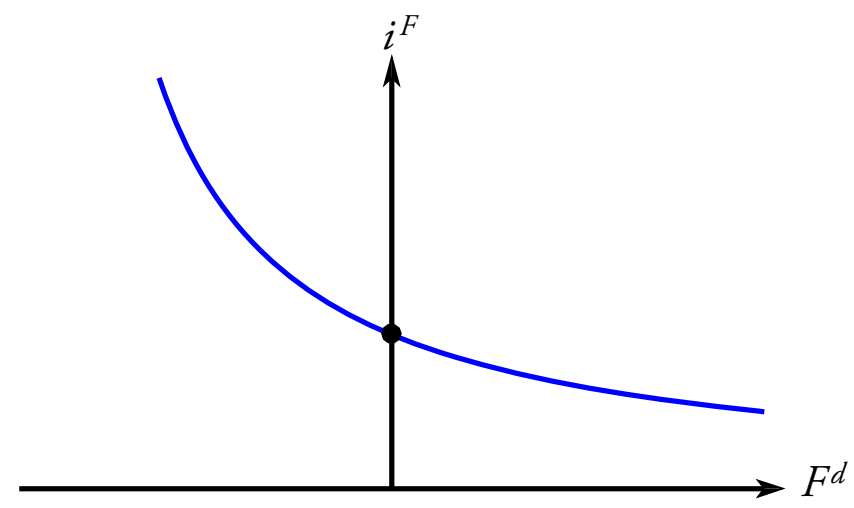

Figure 2: Equilibrium determination of the effective funds rate.

As an intermediate summary, opening a market for borrowed funds converts the shadow price of reserves into an explicit market price whose value is determined by the equilibrium condition, (9). As opposed to the traditional model, each bank is now satisfied with its reserve balances so that the disequilibrium mentioned by Gurley and Shaw disappears.

Combining equations (5) and (8) yields the equilibrium funds rate as a function of the bond interest rate, the amount of reserves, and the required reserve ratio:

$$
i_{t}^{F}=\frac{i_{t}-J^{\prime}\left(R_{t}+B_{t}^{b}\right)}{r r} .
$$

This equation gives the spread between the bonds rate and the funds rate. In accordance with the well-known market segmentation hypothesis, the model treats the funds market and the bonds market as entirely separated. The funds market is a closed loop; non-banks have no access to it and do not desire overnight loans. Three interesting conclusions emerge:

- First, $\partial i_{t}^{F} / \partial i_{t}>0$; the effective funds rate responds positively to the bond interest rate. Higher bond interest makes reserves more valuable for banks.

- Second, $\partial i_{t}^{F} / \partial R_{t}<0$ because higher reserves boost deposits and increase marginal costs; the effective funds rate responds negatively to the amount of reserves. 
- Third, there is nothing unusual about an overnight interbank rate that exceeds the bond market rate. As a numerical example, consider $r r=1 / 3$ and $J^{\prime}\left(D_{t}\right)=2 \%$, which implies $i_{t}^{F}=3\left(i_{t}-2 \%\right)$. At a bond market rate of 5\%, banks would offer up to $9 \%$ in the federal funds market because each additional reserve unit enables them to expand credit by three units that earn a net return of $9 \%$.

\section{Central Bank Funds Rate Management}

The preceding section considered a setting where the Fed selected the level of reserves and accepted the equilibrium funds rate. However, the model is also useful to analyze central bank interest management. By adjusting the amount of reserves as its instrument, the Fed is in a position to stipulate a certain interest rate target and to keep the effective funds rate in the neighborhood of this target. Specifically, any increase in reserves diminishes the effective funds rate, as shown at the end of the preceding section, and vice versa. Figure 3 shows how interest management works. With $R^{1}$ denoting the original level of reserves, the resulting effective funds rate is given by the intersection of the upper demand curve with the ordinate. If the Fed's target funds rate corresponds to the lower bullet point, it can implement this target by providing reserves of the amount $R^{2}>R^{1}$, thus shifting the demand curve to the lower position. As a result, the effective funds rate falls to the desired level.

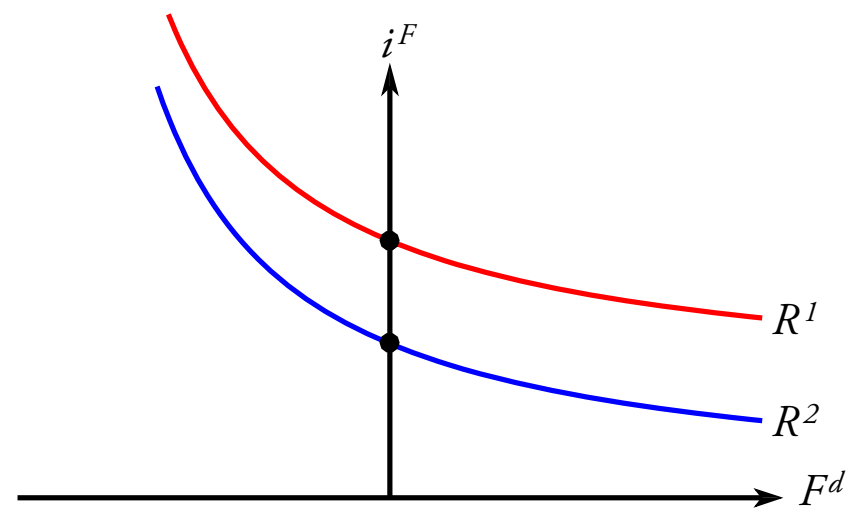

Figure 3: Pursuance of an interest target by means of reserve adjustment.

As the central bank must keep the commercial banks on their demand curves, the total amount of reserves, $R_{t}+F_{t}$, becomes endogenous to the extent that the Fed sets a target funds rate and defends it by suitable open market operations (or by direct credit provision through the discount window). As described in Ihrig et al. (2015), the Fed normally influences the effective funds rate through modest open market operations that affect bank reserves. The resulting short-run endogeneity of reserves characterizes contemporary monetary policies where central banks adjust the level of reserves to the current demand of commercial banks, especially to take account of seasonal fluctuations. Of course, as long as the Fed sets its target funds rate with a view to inflation, reserves are not endogenous in the medium to long run but are the system's ultimate nominal anchor. Short-run frictions aside, all nominal variables are linear functions of the money base. Denying this would imply that the distinct monetary 
performances of, say, Switzerland and Venezuela during the last decades were the result of pure chance.

If the Fed increases the target funds rate at a more or less unchanged bond interest rate, as during 2004-2007, it can implement this policy decision by reducing bank reserves (or, in a growing economy, by increasing them at a slower pace). Formula (10) suggests that restricting reserves induces the effective funds rate to climb even if the bond interest rate remains constant. Hence, if the effective funds rate happens to exceed the bond interest rate, this indicates a monetary restriction. As the demand for reserves stems from a unique statutory requirement, the effective funds rate can sharply deviate from the bond interest rate that is determined by intertemporal exchange motives.

To summarize the most important result of this section, there exists a one-to-one correspondence between the effective funds rate and the level of reserves. This correspondence, which holds in normal times when the effective funds rate happens to be strictly positive, implies that the Fed can either control the effective funds rate, or the level of reserves, but not both. As an illustration of this key point, consider the behavior of the effective funds rate after September 2008.

Figure 4 shows that the Fed kept its target funds rate strictly positive until 13 December 2008 but was unable to defend the respective targets thereafter because it expanded reserves drastically through large-scale asset purchases. This QE policy pushed the effective funds rate considerably below the target rate; the Fed failed to defend its interest target because commercial banks operated on their demand curves for reserves. Effective from 13 December 2008, the Fed recognized that conventional interest policies were incompatible with QE, so it repealed the target funds rate and replaced it by a corridor of $0-0.25$ percent.

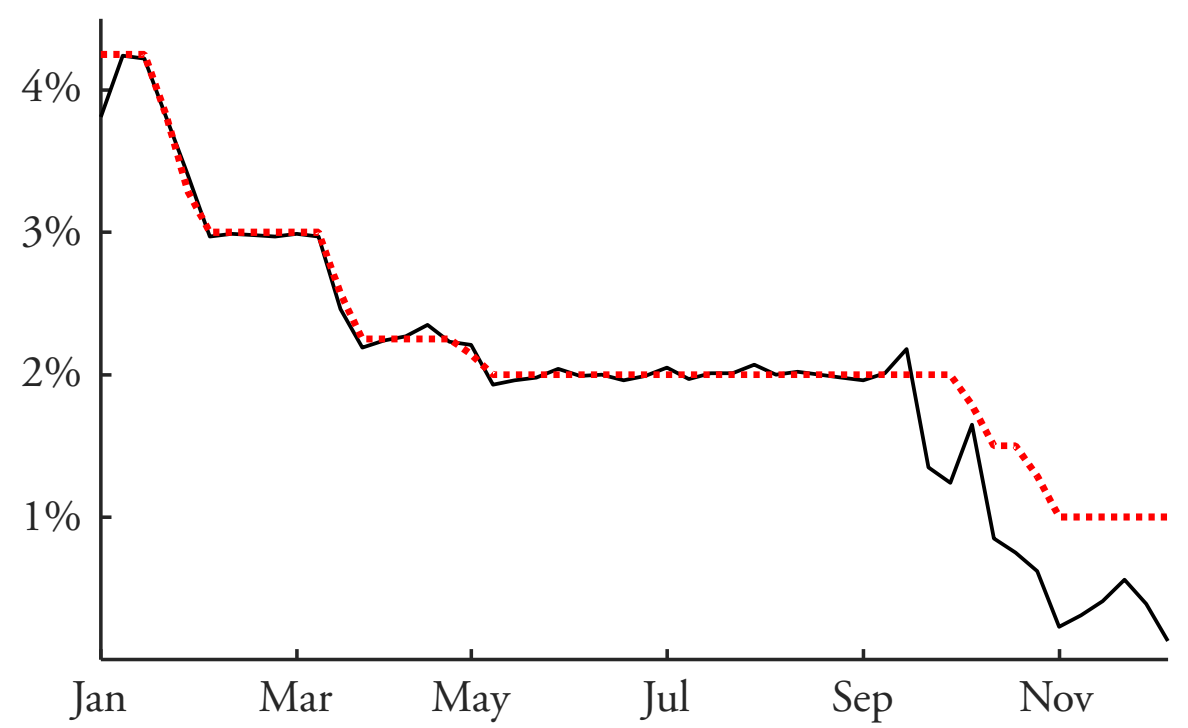

Figure 4: United States 2008 effective funds rate (solid line) vs. target funds rate (dotted line). Notes: Weekly data, retrieved July 2016 from research.stlouisfed.org/fred2, series DFF and DFEDTAR. 
Consistent with the view that banks hold only a trifling amount of excess reserves in normal times, which result from stochastic cash flows, US banks kept excess reserves of only $\$ 2$ bn. in early September 2008. By 1 October 2008, this figure had risen to $\$ 135$ bn. The sharp increase in reserves, documented in figure 5 below, accords with the implication of formula (10) that boosting reserves will depress the effective funds rate and will render a conventional interest target policy infeasible.

\section{Pushing on a String}

The ZLB interest regime that emerged in winter 2008 accords well with the model prediction that a vanishing effective funds rate indicates the presence of excess reserves. However, the unprecedented amount of excess reserves did not entail a comparable expansion of deposits, and inflation stayed away.

This section considers one of several possible explanations of why enormous increases in the money base failed to produce in the money stock and inflation. It starts from the observation that banks must keep their leverage in a range acceptable for markets and regulators. In a model without explicit equity, leverage requirements restrict commercial banks' total liabilities by some given limit, $L$. For banks borrowing in the funds market, total liabilities equal $D_{t}+F_{t}^{d}$; for lending banks, they equal $D_{t}$ because lending constitutes an asset swap. With limited leverage, each bank solves (6) under the additional constraint $D_{t}+\max \left\{F_{t}^{d} ; 0\right\} \leq L$. The associated Lagrange function reads

$$
\begin{aligned}
\mathcal{L}=i_{t} B_{t}^{b}-i_{t}^{F} F_{t}^{d}-J\left(R_{t}+B_{t}^{b}\right)- & \xi_{t}^{R}\left(\operatorname{rr}\left(R_{t}+B_{t}^{b}\right)-R_{t}-F_{t}^{d}\right) \\
& -\xi_{t}^{L}\left(R_{t}+B_{t}^{b}+\max \left\{F_{t}^{d} ; 0\right\}-L\right) .
\end{aligned}
$$

Now, any increase in reserves slackens the first constraint and tightens the second. With a small amount of reserves, the reserve requirement binds and the leverage requirement has slack. As $\xi_{t}^{L}$, the shadow price of the leverage requirement, vanishes in this case, the solutions are still given by (5) and (8).

If the central bank conducts large-scale asset purchases, however, the reserve requirement eventually gets slack and only the leverage requirement binds. Considering $\xi_{t}^{R}=0$ and differentiating with respect to the bond demand yields

$$
\xi_{t}^{L}=i_{t}-J^{\prime}\left(R_{t}+B_{t}^{b}\right)>0 \text {. }
$$

To characterize the associated equilibrium in the federal funds market, one needs a direct argument because the leverage requirement is non-differentiable at the origin: No $i_{t}^{F}>0$ is compatible with a funds market equilibrium, $F_{t}^{d}=0$, since every bank can increase profit by lending a small amount, $F_{t}^{d}<0$, which preserves the reserve requirement and has no influence on the leverage requirement. For $i_{t}^{F}=0$, by contrast, $F_{t}^{d}=0$ is weakly optimal for each bank, which can be seen as follows: First, interbank borrowing and lending leaves profit and the reserve requirement $\left(\xi_{t}^{R}=0\right)$ unaffected. Second, interbank borrowing tightens the leverage requirement and makes 
banks worse off. Third, interbank lending has no influence on the leverage requirement. Since negative rates were ruled out by assumption, this completes the argument and shows that an effective funds rate at the ZLB is the unique equilibrium.

Quantitative easing drives banks into a regime where their inclination to expand credit and deposits is not restricted by the level of reserves but by their leverage. As long as the leverage requirement binds, further increases in bank reserves have no effect on credit and money and leave the effective funds rate at the ZLB.

The upshot of this approach is the characterization of the effective funds rate as a Lagrange multiplier. According to Kuhn-Tucker's complementary slackness condition, the product $\xi_{t}^{R} \times\left(r r\left(R_{t}+B_{t}^{b}\right)-R_{t}-F_{t}^{d}\right)$ always vanishes. Two cases need to be distinguished:

- First, if the effective funds rate, which equals $\xi_{t}^{R}$, is strictly positive, the reserve requirement binds, and there are no excess reserves. This was true until September 2008, when the Fed influenced the funds rate through moderate open market operations.

- Second, if the reserve requirement gets slack, so that excess reserves emerge, the effective funds rate must vanish. Such a situation arose in September 2008.

The evidence reported in figure 5 sustains this theory. It demonstrates that the decline in the effective funds rate to zero and the rise in excess reserves from zero to unprecedented heights took place simultaneously.

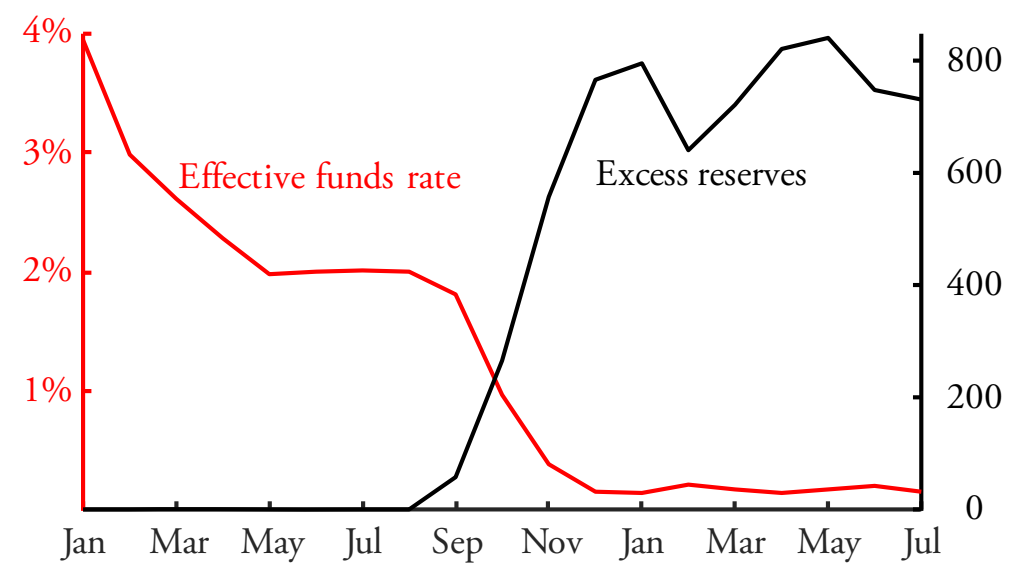

Figure 5: Effective funds rate 2008 in percent (decreasing line, left-hand scale) and excess reserves in billion dollars (increasing line, right-hand scale). Notes: Monthly data, retrieved August 2016 from research.stlouisfed.org/fred2, series DFF and EXCSRESNS.

\section{Interest on Reserves}

Effective from 17 December 2015, the Fed increased the target corridor for the effective funds rate from $0-0.25$ to $0.25-0.50$ percent. The effective funds rate, which fluctuated somewhat, rose by about 0.25 percent, contradicting the claim that its unique equilibrium value were zero. To reconcile this finding with the preceding theory, one must observe that the Fed also increased the interest on required and excess reserve balances from 0.25 to 0.50 . To take account of this additional instrument, a term 
$i_{t}^{R}\left(R_{t}+F_{t}^{d}\right)$ is added to the profit function in (11), where the new symbol $i_{t}^{R}$ indicates the interest rate on reserve balances. With an argument that parallels the above reasoning, the effective funds rate now is characterized as follows:

$$
i_{t}^{F}=\xi_{t}^{R}+i_{t}^{R} .
$$

The intuition behind this reasoning is obvious: If reserves are superabundant so that the Lagrange multiplier, $\xi_{t}^{R}$, vanishes, no bank will lend reserves to a fellow bank at a rate $i_{t}^{F}<i_{t}^{R}$, and no bank will borrow at a rate $i_{t}^{F}>i_{t}^{R}$. If reserves are scarce, however, the funds rate can exceed the interest rate on reserves. In this case, lifting the interest rate on reserves ceteris paribus will diminish the Lagrange multiplier, $\xi_{t}^{R}$, commensurately and will leave the funds rate unaffected. Since any change in interest on reserves is fully absorbed by a response of the effective funds rate, raising the target funds rate together with the interest rate on reserves does not prevent banks from increasing credit and deposits after a relaxation of the leverage constraint. Therefore, it is unclear whether such a policy can forestall inflationary pressures.

\section{Conclusion}

This paper provided a first step toward a theory of the effective funds rate. The latter is often identified with the target funds rate, a policy variable, but such a simplification has two disadvantages. First, it masks the economic mechanism that lifts or reduces the effective funds rate to the target level. While all verbal descriptions of central bank policies identify this mechanism as operating through changes in reserves induced by central bank open market operations, the literature offers no formal model how this works. Second, equalizing the effective and the target funds rate contradicts situations where the two rates differ persistently, as in figure 4.

By characterizing the effective funds rate as a Lagrange multiplier, the model developed here offers a simple explanation in terms of Kuhn-Tucker's complementary slackness condition. From September 2008 on, the Fed raised bank reserves to unprecedented heights. This caused the aggregate reserve requirement to slacken, and from the complementary slackness it follows that the effective funds rate plunged toward the ZLB. By introducing interest on reserves, it becomes possible to detach the effective funds rate from the Lagrange multiplier and to lift it into positive territory. In the presence of excess reserves, however, a positive effective funds rate fails to indicate that reserves are scarce; nominal variables a no longer anchored in the traditional manner.

In the present model, the effective funds rate indicates the scarcity of reserves, while the bond market rate indicates the scarcity of credit. Owing to the adoption of the market segmentation hypothesis, it turned out that the former rate may fall short of the latter, or may exceed it. Thus, the implied yield spread is not a matter of credit durations but governed by the relative scarcity of reserves and credit. An interesting extension of the model would introduce an explicit time structure, combined with arbitrage opportunities of the kind that private creditors and debtors can link their credit contracts to the effective funds rate. Then, an explicit term structure of interest 
rates would emerge, which would be influenced by expectations on the one hand and the relative scarcity of reserves and credit on the other.

\section{References}

Fama, E. F. (2013) Does the Fed Control Interest Rates? Review of Asset Pricing Studies 3: $180-199$.

Goda, T., P. Lysandrou, and C. Stewart (2013) The Contribution of US Bond Demand to the US Bond Yield Conundrum of 2004-2007: An Empirical Investigation. Journal of International Financial Markets, Institutions \& Money 27: 113-136.

Gurley, J. G. and E. S. Shaw (1960) Money in a Theory of Finance, Washington: Brookings.

Ihrig, J. E., E. E. Meade, and G. C. Weinbach (2015) Rewriting Monetary Policy 101: What's the Fed's Preferred Post-Crisis Approach to Raising Interest Rates? Journal of Economic Perspectives 29: 177-198.

Hamilton, J. D. (1996) The Daily Market for Federal Funds. Journal of Political Economy 104: 25-56.

Phillips, C. A. (1920) Bank Credit. New York: Macmillan.

Poole, W. (1968) Commercial Bank Reserve Management in a Stochastic Model: Implications for Monetary Policy. Journal of Finance 23: 769-791.

Rudebusch, G. D. (1995) Federal Reserve Interest Rate Targeting, Rational Expectations, and the Term Structure. Journal of Monetary Economics 35: 245-274. 